\title{
Articles
}

\section{Mediators of the Link Between Adult Attachment and Mindfulness}

\author{
Jon G. Caldwell ${ }^{\star a}$, Phillip R. Shaver ${ }^{b}$
}

[a] The Meadows Treatment Center, Wickenburg, Arizona, USA. [b] Department of Psychology, University of California, Davis, USA.

\begin{abstract}
The capacity to be mindfully aware of the present moment without judgment is associated with a number of positive psychological and physiological outcomes. Experiences in attachment relationships are related to specific cognitive-emotional patterns that may contribute to dispositional mindfulness. A sample of adults $(N=93)$ completed questionnaires regarding adult attachment, rumination, thought suppression, attentional control, and mindfulness. Attachment-related avoidance predicted lower levels of mindfulness, a relation mediated by thought suppression and poorer attentional control. Attachment-related anxiety also predicted lower levels of mindfulness, a relation mediated by rumination and poorer attentional control. The results suggest that in the context of insecure attachment relationships thought suppression and rumination defend against personal and interpersonal losses by deactivating (in the case of avoidance) or hyperactivating (in the case of anxiety) the attachment system. These habitual defensive patterns may be important links between adult attachment orientations and mindfulness.
\end{abstract}

Keywords: mindfulness, attachment, adult attachment, rumination, thought suppression, attentional control, emotion, emotion regulation

Interpersona, 2013, Vol. 7(2), 299-310, doi:10.5964/ijpr.v7i2.133

Received: 2013-07-16. Accepted: 2013-11-17. Published (VoR): 2013-12-20.

${ }^{*}$ Corresponding author at: The Meadows Treatment Center, Department of Psychiatry, 1655 North Tegner Street, Wickenburg, Arizona 85390. E-mail: drjoncaldwell@gmail.com

This is an open access article distributed under the terms of the Creative Commons Attribution License

(http://creativecommons.org/licenses/by/3.0), which permits unrestricted use, distribution, and reproduction in any medium, provided the original work is properly cited.

\section{Introduction}

In recent decades, there has been an explosion of interest in mindfulness practices, in both the scientific community and the general public. Extensive research has shown that mindfulness practices are associated with a number of positive outcomes related to mental, emotional, physical and social health (see Keng, Smoski, \& Robins, 2011, for a review). Mindfulness is usually defined as bringing one's full attention to experiences in the present moment, in a nonjudgmental or accepting way (Baer, Smith, Hopkins, Krietemeyer, \& Toney, 2006; Brown \& Ryan, 2003; Kabat-Zinn, 1994). The term mindfulness may be used to describe (a) a psychological trait (sometimes called "dispositional mindfulness"), (b) a contemplative practice (e.g., mindfulness meditation), or (c) a particular state of awareness (Germer, Siegel, \& Fulton, 2005). Levels of trait mindfulness vary widely across individuals, yet we know relatively little about what factors contribute to it.

In this article, we explore the possibility that experiences in close relationships (in particular, attachment relationships) affect one's capacity for mindfulness. There is already considerable evidence that close relationships with caregivers and romantic partners shape how children and adults perceive themselves, other people, and the world (see Cassidy \& Shaver, 2008, for a review). For example, people who have experienced secure attachment rela- 
tionships, characterized by warmth, openness, trust, and safety, approach their experiences with non-defensive curiosity and an expectation that challenges can be managed effectively (Shaver \& Mikulincer, 2002). Given their history of attachment security, such individuals are better equipped to have acceptance and compassion for themselves and others (Mikulincer \& Shaver, 2005) and to meet adversity with greater equanimity and resilience (Caldwell \& Shaver, 2012; Mikulincer \& Shaver, 2007a).

In contrast, people who have experienced insecure attachment relationships, in which warmth, openness, trust, and safety were inconsistent or lacking, may have adapted to these suboptimal relationships by employing defensive cognitive and emotional strategies for maintaining interpersonal connections while protecting against rejection, loss, and shame (Mikulincer \& Shaver, 2003). Over time, these cognitive-emotional patterns, formed in the context of insecure attachment relationships, may contribute to a diminished capacity for open, flexible, and non-judgmental awareness of one's internal and external worlds.

Adult attachment orientations can be reliably measured in terms of two dimensions: attachment anxiety and avoidance (Brennan, Clark, \& Shaver, 1998; Fraley \& Shaver, 2000). Individuals who score low on both dimensions are considered secure with respect to attachment, whereas individuals who score high on one or both dimensions are considered to be insecure. Although genes may have some influence on the development of these adult attachment styles (e.g., Gillath, Shaver, Baek, \& Chun, 2008), their formation is thought to be primarily related to experiences in close relationships (Mikulincer \& Shaver, 2007b).

For example, in circumstances where an attachment figure is inconsistently available, physically or emotionally, a person may implicitly adopt hyperactivating attachment strategies involving amplification of attachment needs, high levels of negative emotion, persistent attempts to maintain connection, and intense fear of abandonment (Cassidy \& Kobak, 1988). Although these strategies may be adaptive in the context of an elusive and inconsistent attachment figure, they may incur psychological costs in other contexts.

In situations where an attachment figure is consistently dismissive, neglectful, or abusive, a person may develop deactivating attachment strategies that involve down-playing attachment needs, hiding vulnerabilities, remaining emotionally detached and aloof, and avoiding closeness and intimacy (Cassidy \& Kobak, 1988). These deactivating strategies can be adaptive when the potential for dismissal and rejection are high, but they can have negative consequences in other situations.

In a study of 388 young adults, Caldwell and Shaver (2012) used structural equation modeling to delineate the hyperactivating and deactivating pathways connecting attachment insecurity with emotion dysregulation and impaired resilience (i.e., the ability to regulate oneself to respond adaptively to situational challenges and affordances). In that study, both attachment anxiety and avoidance were associated with greater difficulties in repairing and recovering from negative emotional states and lower levels of resilience. However, as predicted, the two attachment dimensions were related to those outcome variables through different pathways: attachment-related anxiety had effects via a hyperactivating pathway involving high levels of rumination and high levels of negative emotion. In contrast, attachment-related avoidance had its effects through a deactivating pathway involving high levels of emotional suppression and limited understanding and clarity about emotional states.

Of special interest in the present study, low dispositional mindfulness has been associated with hyperactivating processes such as rumination (Raes \& Williams, 2010) and negative emotion (Brown \& Ryan, 2003), and with deactivating processes such as thought suppression (Feldman, Hayes, Kumar, Greeson, \& Laurenceau, 2007) 
and emotional unclarity (Baer, Smith, \& Allen, 2004). Coffey, Hartman, and Fredrickson (2010) used structural equation modeling to examine a number of possible mediators of the relations between two facets of mindfulness, attention and acceptance, and the dependent variables of flourishing and psychological well-being. The model that best accounted for this relation included the mediating variables of rumination, negative emotion, and emotional unclarity (these authors did not include emotional suppression or thought suppression as possible mediators). Therefore, rumination, negative emotion, suppression, and unclarity may be important links between adult attachment orientations and dispositional mindfulness.

Another contributing factor to the putative relationship between attachment insecurity and lower levels of mindfulness may be attentional control, which can be thought of as the general capacity to regulate attention in relation to positive as well as negative emotional processes (Derryberry \& Reed, 2002). Studies have shown that adult attachment insecurity is related to poor attentional control, whereas attachment-related security is associated with more open and flexible attention (Edelstein \& Gillath, 2008; Fraley \& Shaver, 1997; Gillath, Bunge, Shaver, Wendelken, \& Mikulincer, 2005). We posit that the defensive maneuvering inherent in hyperactivating (anxious) and deactivating (avoidant) attachment strategies deplete attentional resources, leaving people with less capacity for mindful awareness. Supporting this assertion, research has shown that rumination and suppression both disrupt the regulation and allocation of attentional resources (see Chambers, Gullone, \& Allen, 2009, for a review). Thus, attachment-related anxiety and avoidance are associated, respectively, with the hyperactivating tendency to ruminate and the deactivating tendency to suppress, and these tendencies are related to lower levels of attentional control and mindfulness.

In line with the reasoning behind the present study, Walsh, Balint, Smolira, Fredericksen, and Madsen (2009) found that lower levels of self-reported parental nurturance correlated with lower levels of both attentional control and dispositional mindfulness. In a separate sample, they found that dispositional mindfulness was inversely correlated with attachment-related avoidance and anxiety, and trait anxiety and attachment-related anxiety (but not avoidance) predicted diminished mindfulness in a regression analysis. Shaver, Lavy, Saron, and Mikulincer (2007) reported robust correlations between mindfulness and attachment-related anxiety and avoidance. Moreover, when they regressed mindfulness onto the two insecurity dimensions, attachment-related anxiety and avoidance, both contributed uniquely to mindfulness and together accounted for $42 \%$ of the variance in mindfulness. Although these preliminary data confirm that attachment insecurity is related to lower levels of mindfulness, we still know relatively little about mediating variables.

In the present study, we hypothesized that attachment anxiety and avoidance would independently predict mindfulness in a regression analysis. And, building on previous research (Caldwell \& Shaver, 2012), we anticipated that attachment-related anxiety would be related to the hyperactivating variable rumination, whereas attachmentrelated avoidance would be related to the deactivating variable thought suppression. (We assessed rumination and thought suppression because we wanted to focus on the cognitive, rather than the emotional, aspects of the attachment-mindfulness association.) We hypothesized that the insecure attachment dimensions, rumination, and thought suppression would all be associated with lower levels of attentional control and mindfulness. Finally, we predicted that rumination and attentional control would mediate the relation between attachment-related anxiety and mindfulness, whereas thought suppression and attentional control would mediate the relation between attachment-related avoidance and mindfulness. 


\section{Methods}

\section{Participants}

A total of 93 students completed questionnaires in exchange for credit in a university course about emotions. Of the 93 participants, $72(77 \%)$ were female, $20(22 \%)$ were male, and $1(1 \%)$ did not disclose a gender. The participants' ages ranged from 19 to 45 , with a mean of $22.08(S D=3.26)$. The sample's ethnic make-up was representative of the student body at the university and included 37 (40\%) White/Caucasian, 33 (36\%) Asians or Asian Americans, 15 (16\%) Hispanic or Latino/a individuals, 1 (1\%) Native Hawaiians or Other Pacific Islanders, 1 (1\%) American Indian, 1 (1\%) Black/African Americans, 1 (1\%) Other, and 4 (4\%) undeclared. Regarding romantic relationship status, $61(66 \%)$ participants reported being in a close relationship at the time of the study, and the average length of that relationship was $31.74(S D=56.86)$ months.

\section{Measures}

The Experiences in Close Relationships Inventory (ECR) - The ECR (Brennan et al., 1998) is a 36-item questionnaire that assesses attachment-related anxiety (with 18 items, such as "I worry about being abandoned") and avoidance (with 18 items, such as "I prefer not to show a partner how I feel deep down"). Items were rated on a 7-point Likert scale ranging from 1 (disagree strongly) to 7 (agree strongly). In the present sample, the Cronbach alpha (internal reliability) coefficient for the anxiety scale was .90 and for the avoidance scale, .91.

The Ruminative Response Scale (RRS) - The RRS (Nolen-Hoeksema \& Morrow, 1991) is a 22-item scale that assesses the tendency to ruminate in response to sad and depressed mood. In the present study, we used the 5 -item brooding rumination subscale, which assesses the tendency to ruminate in self-critical ways (e.g., "Why do I always react this way?"). Respondents indicate how often they engage in each of the examples of rumination using a 4-point rating scale ranging from 1 (almost never) to 4 (almost always). The brooding rumination subscale had an alpha coefficient of .63.

The White Bear Suppression Inventory (WBSI) - The WBSI (Wegner \& Zanakos, 1994) is a 15-item measure of the tendency to experience unwanted and intrusive thoughts. Items were rated on a 7-point scale ranging from 1 (disagree strongly) to 7 (agree strongly). Recent investigations into the psychometric properties of the WBSI (Schmidt et al., 2009) have shown that it contains a 9-item subscale measuring the wish to suppress unwanted thoughts (e.g., "There are things I prefer not to think about"). In the present study, this subscale had an alpha coefficient of .86 .

The Attentional Control Scale (ACS) - The ACS (Derryberry \& Reed, 2002) is a 20-item, single-factor measure that includes items related to attentional focusing (e.g., "My concentration is good even if there is music in the room around me"), attention shifting (e.g., "After being distracted or interrupted, I can easily shift my attention back to what I was doing"), and flexible control of thought (e.g., "I can become interested in a new topic very quickly if I need to"). The scale has been shown to predict better control of attention on Stroop-like tasks (e.g., Derryberry \& Reed, 2002). Each item consists of a statement rated on a 1-7 disagree-agree scale. The alpha coefficient for the ACS was .86 in the present study.

The Mindful Attention Awareness Scale (MAAS) - The MAAS (Brown \& Ryan, 2003) is a 15-item, single-factor measure of dispositional mindfulness. Participants in the present study used a scale ranging from 1 (disagree strongly) to 7 (agree strongly) to rate such items as "I find myself preoccupied with the future or the past" and "I 
tend to walk quickly to get where I'm going without paying attention to what I experience along the way." The scale authors found that scores were significantly higher for practitioners of mindfulness meditation than for non-meditator control groups (Brown \& Ryan, 2003). All items were scored in the present study so that higher scores indicate higher levels of mindfulness. The MAAS had an alpha coefficient of .80 .

\section{Results}

\section{Correlation Analyses}

The means, standard deviations, and Pearson correlations (evaluated with two-tailed significance tests) among the study's main variables are presented in Table 1. As predicted, attachment-related avoidance correlated with thought suppression (but not rumination), whereas attachment-related anxiety correlated with rumination (but not thought suppression). Also, both insecure attachment dimensions were inversely correlated with attentional control and mindfulness. Rumination, thought suppression, and attentional control were all correlated with mindfulness in the expected directions.

Table 1

Means, Standard Deviations, and Correlations Among Study Variables

\begin{tabular}{|c|c|c|c|c|c|c|}
\hline Measure & 1 & 2 & 3 & 4 & 5 & 6 \\
\hline 1. Attachment Avoidance & - & $.27^{\star \star}$ & .17 & $.29^{* *}$ & $-.32^{* *}$ & $-.33^{* *}$ \\
\hline 2. Attachment Anxiety & & - & $.35^{\star \star}$ & .17 & $-.53^{* *}$ & $-.27^{\star *}$ \\
\hline 3. Rumination & & & - & $.51^{* *}$ & $-.22^{*}$ & $-.30^{* *}$ \\
\hline 4. Thought Suppression & & & & - & -.08 & $-.28^{* *}$ \\
\hline 5. Attentional Control & & & & & - & $.33^{* *}$ \\
\hline 6. Mindfulness & & & & & & - \\
\hline Mean & 3.11 & 3.92 & 2.28 & 4.63 & 3.71 & 4.26 \\
\hline$S D$ & .98 & .99 & .56 & 1.11 & .78 & .81 \\
\hline
\end{tabular}

${ }^{*} p<.05 .{ }^{* *} p<.01$.

\section{Regression Analysis}

When mindfulness was regressed onto the two adult attachment dimensions, the entire model was significant $F(2,90)=7.46, p<.001$, and attachment-related avoidance made a unique and significant contribution to mindfulness, $\beta=-.28, t(90)=-2.73, p=.008$. Attachment-related anxiety's unique influence on mindfulness fell just above the .05 level of significance, $\beta=-.19, t(90)=-1.90, p=.06$. Attachment-related avoidance and anxiety together explained $14 \%$ of the variance in mindfulness $\left(R^{2}=14.2\right)$

\section{Mediation Analyses}

We conducted two sets of mediational analyses to examine, first, whether the relation between attachment-related avoidance and mindfulness was mediated by thought suppression and attentional control and, second, whether the relation between attachment-related anxiety and mindfulness was mediated by rumination and attentional control. These analyses were based on a bootstrapping method recommended for smaller samples (MacKinnon, Lockwood, Hoffman, West, \& Sheets, 2002; Preacher \& Hayes, 2004) and were computed with an SPSS macro that estimates direct and indirect effects with multiple mediators (Preacher \& Hayes, 2008). The bootstrap estimates presented here are based on 5,000 bootstrap samples. Statistical significance with alpha set at .05 is indicated 
by the $95 \%$ bias corrected $(\mathrm{BC})$ confidence intervals $(\mathrm{Cl})$ not crossing zero. (See Figure 1 for graphical displays of both mediation models.)

The mediation model involving attachment-related avoidance was significant overall $F(3,89)=7.64, p<.001$ and accounted for $18 \%$ of the variance in mindfulness. The total effect of attachment-related avoidance on mindfulness (c path), $\beta=-.27, p<.001$, became non-significant (c' path), $\beta=-.15, p=.07$, when the mediators of thought suppression and attentional control were included in the model. The total indirect effect through the two mediators was significant, with a point estimate (PE) of -.1152 and a $95 \% \mathrm{BC} / \mathrm{Cl}$ of -.2377 to -.0395 . The specific indirect effects of thought suppression (PE $=-.0488, \mathrm{BC} / \mathrm{Cl}=-.1366$ to -.0034$)$ and attentional control $(\mathrm{PE}=-.0665, \mathrm{BC} / \mathrm{Cl}$ $=-.1417$ to -.0204 ) were both significant. These results indicate that thought suppression and attentional control both significantly mediated the relation between attachment-related avoidance and mindfulness.

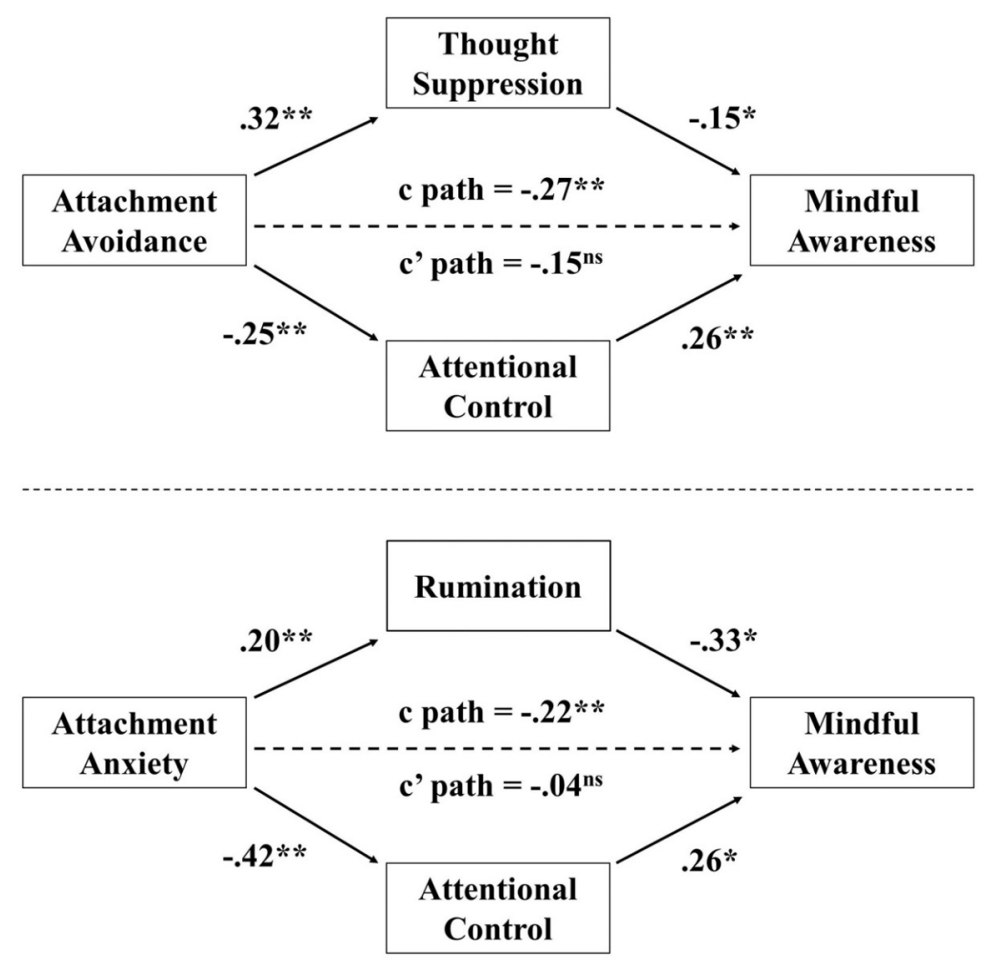

Figure 1. Mediation models for attachment-related avoidance and anxiety predicting mindfulness. Standardized regression coefficients $(\beta)$ are shown above the pathways. The $c$ path represents the effect of adult attachment on mindfulness without the mediators (total effect) and the c' path is the effect of adult attachment on mindfulness after accounting for the mediators (direct effect).

The mediation model involving attachment-related anxiety was also significant overall, $F(3,89)=5.97, p<.001$, and accounted for $17 \%$ of the variance in mindfulness. The total effect of attachment-related anxiety on mindfulness (c path), $\beta=-.22, p<.01$, became non-significant (c' path), $\beta=-.04, p=.66$, when the mediators of rumination and attentional control were included in the model. The total indirect effect through the two mediators was significant $(P E=-.1750, B C / C l=-.3145$ to -.0689$)$. The specific indirect effects of rumination $(P E=-.0659, B C / C l=-$ .1657 to -.0091$)$ and attentional control ( $P E=-.1091, \mathrm{BC} / \mathrm{Cl}=-.2218$ to -.0251 ) were both significant. These results indicate that rumination and attentional control both significantly mediated the relation between attachment-related anxiety and mindfulness. 


\section{Discussion}

Due to a resurgence of interest in contemplative practices and mounting scientific evidence of their positive benefits, mindfulness is now widely recognized as a powerful way to promote health and well-being. Previous experiences in attachment relationships are likely to shape a person's capacity for mindful awareness, yet there has been relatively little research on this possibility. In fact, to our knowledge this study is one of only a handful to investigate the links between adult attachment and mindfulness and the first to investigate possible mediators of this relation.

In the present study, adult attachment insecurity was related to lower levels of mindful awareness, but when both dimensions were entered into a regression model predicting mindfulness, the unique effect of attachment-related avoidance was significant, whereas that of attachment-related anxiety was only marginally significant. Conversely, Walsh et al. (2009) found that attachment-related anxiety independently predicted mindfulness, whereas the unique effect of attachment-related avoidance was non-significant. Given that their sample was recruited from the United Kingdom and ours from the United States, this discrepancy might be explained by differences in sample characteristics (e.g., ethnicity, relationship status) or cultural differences in attachment styles (Del Giudice, 2011; Schmitt et al., 2004).

Different still are the findings reported by Shaver et al. (2007), showing that both attachment dimensions independently and robustly predicted mindfulness. In this case, the discrepant results may be related to these authors' use of the Five-Facet Mindfulness Questionnaire (FFMQ: Baer, Smith, Hopkins, Krietemeyer, \& Toney, 2006), whereas we used the MAAS in the present study. Moreover, Shaver et al.'s sample comprised relatively older adults who were willing and able to attend a 3-month, full-time meditation retreat. Thus, participants in their sample likely had more interest in, and experience with, mindfulness and more life experience as well. The distinction between meditators and non-meditators has been shown to influence item-response tendencies on mindfulness questionnaires (Baer et al., 2008; Van Dam, Earleywine, \& Danoff-Burg, 2009) and may account for the relatively larger portion of variance explained in the Shaver et al. (2007) study $\left(R^{2}=42 \%\right)$, versus $18 \%$ in the study by Walsh et al. (2009), which included trait anxiety as a co-predictor, and $14 \%$ in the present study.

Attachment-related avoidance was associated here with the tendency to suppress unwanted thoughts, but it was not related to rumination. The opposite pattern emerged for attachment-related anxiety, which was significantly correlated with self-critical rumination but not with thought suppression. Congruent with previous research (Caldwell \& Shaver, 2012) and adult attachment theory more generally, these findings indicate that people scoring high in attachment-related avoidance have developed a tendency to deactivate their attachment system in response to a history of insecure relationships, partly through habitual suppression of unwanted thoughts. Due to strong feelings of distrust of others, these individuals actively avoid and dismiss thoughts and feelings that could lead to closeness and interdependence. The act of suppressing potentially threatening information and keeping it out of awareness requires the allocation and maintenance of cognitive resources (Ochsner \& Gross, 2005), which can be disrupted and depleted under conditions of elevated cognitive load or intense emotion (Caldwell, Krug, Carter, \& Minzenberg, in press; Edelstein \& Gillath, 2008; Mikulincer, Dolev, \& Shaver, 2004), resulting in the breakdown of attentional control and diminished capacity for self-reflection and mindful awareness.

Along these same lines, individuals scoring high in attachment-related anxiety have implicitly adapted to insecure close relationships by hyperactivating their attachment system, in part through habitual rumination that is often self-critical in nature. Within the context of an inconsistent or unsafe attachment relationship, ruminative processes 
can be viewed as an attempt to keep the fleeting relationship alive and guard against perceived threats of abandonment and loss. Often, individuals who are anxious with respect to attachment ruminate on their personal shortcomings and how they might change themselves or their circumstances to maintain their close relationships. This can result in symptoms of depression and diminished feelings of self-efficacy (Caldwell, Shaver, Li, \& Minzenberg, 2011). Of course, like thought suppression, rumination monopolizes cognitive resources (Levens, Muhtadie, \& Gotlib, 2009), disrupts attentional control, and limits the capacity for nonjudgmental, compassionate, and mindful awareness in the present moment.

These findings were further supported by the results of the mediational analyses, which showed that the relation between attachment-related avoidance and mindfulness was mediated by thought suppression and attentional dyscontrol, whereas the relation between attachment-related anxiety and mindfulness was mediated by rumination and attentional dyscontrol. These results are consistent with studies showing that thought suppression and rumination are associated with lower levels of mindfulness (Feldman et al., 2007). Also, rumination, negative emotion, and a lack of emotional clarity, facets of hyperactivating and deactivating attachment patterns, have been identified as mediating pathways between mindfulness and positive mental health (Coffey et al., 2010). Although these authors did not assess thought or emotion suppression as possible mediating variables, given the significant correlation between these variables and emotional unclarity, we suspect that they may very well play mediating roles as well.

Elsewhere, researchers (Caldwell \& Shaver, 2012; Mikulincer, Shaver, \& Pereg, 2003) have posited that attachment security is related to what Fredrickson (2001) called positive "broaden and build cycles," in which positive beliefs and emotions facilitate self-perpetuating upward spirals of openness and curiosity, and expanded cognitive and behavioral repertoires, which over time results in durable personal resources that enable resilience, social connections, and well-being. Conversely, negative cognitive-emotional patterns, including suppression of unwanted thoughts and self-critical rumination, lead to downward spirals in which attentional resources are hijacked by fears, imagined threats, and beliefs about personal inadequacy, leading to a restricted range of percepts, ideas, and actions. Coffey and her colleagues (2010) recently suggested that mindfulness plays an important role in fostering broaden and build cycles by stimulating positive emotions (e.g., tranquility, joy, loving kindness) and enhancing cognitive flexibility. This line of research is very congruent with our thinking and the data presented here.

The present study raises the interesting possibility that a mindfulness-based intervention might help modify the hyperactivating and deactivating patterns associated with adult attachment insecurity. To this end, Caldwell and Shaver (in press) conducted a wait-list controlled pilot-study of a mindfulness-based intervention for promoting security in adult female survivors of child maltreatment. This three-day program called REAC ${ }^{2} \mathrm{H}$ (Restoring Embodied Awareness, Compassionate Connection and Hope) used a combination of instruction and experiential techniques involving mindfulness and self-compassion to ameliorate the unhealthy cognitive-emotional patterns associated with adult attachment insecurity.

Consistent with the results presented here, correlational analyses of the pre-intervention data from the entire sample showed similar links between attachment-related avoidance and deactivating strategies involving emotion suppression and unclarity, and between attachment-related anxiety and hyperactivating strategies involving rumination and negative emotion. Furthermore, compared to a wait-list control group $(N=22)$ assessed, like the intervention group, at three time points (pre-intervention, one week post intervention, and five weeks post-intervention), the intervention group $(N=17)$ showed significant improvements in rumination, negative emotion (mar- 
ginally significant), emotional suppression, emotional unclarity, emotion regulation, and mindfulness. These results support the findings of the present study and provide preliminary evidence that mindfulness practices promote cognitive-emotional patterns that are more consistent with attachment security.

The present study is not without limitations, of course. First, its study design is cross-sectional and correlational, so inferences about causation cannot be made. We did not gather data regarding participants' preexisting experience with mindfulness, so we could not assess whether the relation between adult attachment and mindfulness was moderated by previous exposure to mindfulness concepts and practice. Although the sample size was limited, our hypotheses were firmly rooted in theory and previous research. Also, we used advanced statistical methods to test multiple mediation, methods that are well-suited to smaller sample sizes, do not rely on the assumption of a normal sampling distribution, and limit the number of inferential tests so that the likelihood of Type 1 error is reduced (MacKinnon et al., 2002; Preacher \& Hayes, 2004; Shrout \& Bolger, 2002). Results may not be broadly generalizable because the majority of study participants were female and young adults. To increase study participation and adherence, we used the single-factor MAAS to measure dispositional mindfulness. Future research might include a multi-dimensional measure like the FFMQ (Baer et al., 2006) to better characterize how adult attachment orientations and mediational processes are related to the various facets of mindfulness.

Limitations notwithstanding, the present study is a useful step in better characterizing the relation between adult attachment and mindfulness. It extends the literature on attachment and mindfulness by identifying mediating variables associated with maladaptive, but potentially modifiable, cognitive-emotional patterns. Like other attachment investigators (Allen \& Miga, 2010), we have advocated for a "move to the level of emotion regulation" in attachment research, a move that, in our opinion, will open the door to more effective clinical interventions for healing attachment-related wounds. Mindfulness may play an important role in this process by shifting peoples' experiences of themselves, others, and their environments in ways that foster personal and interpersonal well-being.

\section{References}

Allen, J. P., \& Miga, E. M. (2010). Attachment in adolescence: A move to the level of emotion regulation. Journal of Social and Personal Relationships, 27, 181-190. doi:10.1177/0265407509360898

Baer, R. A., Smith, G. T., \& Allen, K. B. (2004). Assessment of mindfulness by self-report the Kentucky Inventory of Mindfulness Skills. Assessment, 11, 191-206. doi:10.1177/1073191104268029

Baer, R. A., Smith, G. T., Hopkins, J., Krietemeyer, J., \& Toney, L. (2006). Using self-report assessment methods to explore facets of mindfulness. Assessment, 13, 27-45. doi:10.1177/1073191105283504

Baer, R. A., Smith, G. T., Lykins, E., Button, D., Krietemeyer, J., Sauer, S., . . Williams, J. M. G. (2008). Construct validity of the five facet mindfulness questionnaire in meditating and nonmeditating samples. Assessment, 15, 329-342. doi:10.1177/1073191107313003

Brennan, K. A., Clark, C. L., \& Shaver, P. R. (1998). Self-report measurement of adult attachment: An integrative overview. In J. A. Simpson \& W. S. Rholes (Eds.), Attachment theory and close relationships (pp. 46-76). New York, NY: Guilford Press. 
Brown, K. W., \& Ryan, R. M. (2003). The benefits of being present: Mindfulness and its role in psychological well-being. Journal of Personality and Social Psychology, 84, 822-848. doi:10.1037/0022-3514.84.4.822

Caldwell, J. G., Krug, M. K., Carter, C. S., \& Minzenberg, M. J. (in press). Cognitive control in the face of fear: Reduced cognitive-emotional flexibility in women with a history of child abuse. Journal of Aggression, Maltreatment \& Trauma.

Caldwell, J. G., \& Shaver, P. R. (2012). Exploring the cognitive-emotional pathways between adult attachment and ego-resiliency. Individual Differences Research, 10, 141-152.

Caldwell, J. G., \& Shaver, P. R. (in press). Promoting attachment-related mindfulness and compassion: A wait-list controlled study of women who were mistreated during childhood. Mindfulness.

Caldwell, J. G., Shaver, P. R., Li, C. S., \& Minzenberg, M. J. (2011). Childhood maltreatment, adult attachment, and depression as predictors of parental self-efficacy in a-risk mothers. Journal of Aggression, Maltreatment \& Trauma, 20, 595-616. doi:10.1080/10926771.2011.595763

Cassidy, J., \& Kobak, R. R. (1988). Avoidance and its relation to other defensive processes. In J. Belsky \& T. Nezworski (Eds.), Clinical implications of attachment (pp. 300-323). Hillsdale, NJ: Erlbaum.

Cassidy, J., \& Shaver, P. R. (2008). Handbook of attachment: Theory, research, and clinical applications (2nd ed.). New York, NY: Guilford Press.

Chambers, R., Gullone, E., \& Allen, N. B. (2009). Mindful emotion regulation: An integrative review. Clinical Psychology Review, 29, 560-572. doi:10.1016/j.cpr.2009.06.005

Coffey, K. A., Hartman, M., \& Fredrickson, B. L. (2010). Deconstructing mindfulness and constructing mental health: Understanding mindfulness and its mechanisms of action. Mindfulness, 1, 235-253. doi:10.1007/s12671-010-0033-2

Del Giudice, M. (2011). Sex differences in romantic attachment: A meta-analysis. Personality and Social Psychology Bulletin, 37, 193-214. doi:10.1177/0146167210392789

Derryberry, D., \& Reed, M. A. (2002). Anxiety-related attentional biases and their regulation by attentional control. Journal of Abnormal Psychology, 111, 225-236. doi:10.1037/0021-843X.111.2.225

Edelstein, R. S., \& Gillath, O. (2008). Avoiding interference: Adult attachment and emotional processing biases. Personality and Social Psychology Bulletin, 34, 171-181. doi:10.1177/0146167207310024

Feldman, G., Hayes, A., Kumar, S., Greeson, J., \& Laurenceau, J.-P. (2007). Mindfulness and emotion regulation: The development and initial validation of the Cognitive and Affective Mindfulness Scale-Revised (CAMS-R). Journal of Psychopathology and Behavioral Assessment, 29, 177-190. doi:10.1007/s10862-006-9035-8

Fraley, R. C., \& Shaver, P. R. (1997). Adult attachment and the suppression of unwanted thoughts. Journal of Personality and Social Psychology, 73, 1080-1091. doi:10.1037/0022-3514.73.5.1080

Fraley, R. C., \& Shaver, P. R. (2000). Adult romantic attachment: Theoretical developments, emerging controversies, and unanswered questions. Review of General Psychology, 4(2), 132-154. doi:10.1037/1089-2680.4.2.132

Fredrickson, B. L. (2001). The role of positive emotions in positive psychology: The broaden-and-build theory of positive emotions. The American Psychologist, 56, 218-226. doi:10.1037/0003-066X.56.3.218 
Germer, C. K., Siegel, R. D., \& Fulton, P. R. (2005). Mindfulness and psychotherapy. New York, NY: Guilford Press.

Gillath, O., Bunge, S. A., Shaver, P. R., Wendelken, C., \& Mikulincer, M. (2005). Attachment-style differences in the ability to suppress negative thoughts: Exploring the neural correlates. Neurolmage, 28, 835-847.

doi:10.1016/j.neuroimage.2005.06.048

Gillath, O., Shaver, P. R., Baek, J.-M., \& Chun, D. S. (2008). Genetic correlates of adult attachment style. Personality and Social Psychology Bulletin, 34, 1396-1405. doi:10.1177/0146167208321484

Kabat-Zinn, J. (1994). Wherever you go, there you are: Mindfulness meditation in everyday life. New York, NY: Hyperion.

Keng, S. L., Smoski, M. J., \& Robins, C. J. (2011). Effects of mindfulness on psychological health: A review of empirical studies. Clinical Psychology Review, 31, 1041-1056. doi:10.1016/j.cpr.2011.04.006

Levens, S. M., Muhtadie, L., \& Gotlib, I. H. (2009). Rumination and impaired resource allocation in depression. Journal of Abnormal Psychology, 118, 757-766. doi:10.1037/a0017206

MacKinnon, D. P., Lockwood, C. M., Hoffman, J. M., West, S. G., \& Sheets, V. (2002). A comparison of methods to test mediation and other intervening variable effects. Psychological Methods, 7, 83-104. doi:10.1037/1082-989X.7.1.83

Mikulincer, M., Dolev, T., \& Shaver, P. R. (2004). Attachment-related strategies during thought-suppression: Ironic rebounds and vulnerable self-representations. Journal of Personality and Social Psychology, 87, 940-956.

doi:10.1037/0022-3514.87.6.940

Mikulincer, M., \& Shaver, P. R. (2003). The attachment behavioral system in adulthood: Activation, psychodynamics, and interpersonal processes. Advances in Experimental Social Psychology, 35, 53-152. doi:10.1016/S0065-2601(03)01002-5

Mikulincer, M., \& Shaver, P. R. (2005). Attachment security, compassion, and altruism. Current Directions in Psychological Science, 14, 34-38. doi:10.1111/j.0963-7214.2005.00330.x

Mikulincer, M., \& Shaver, P. R. (2007a). Boosting attachment security to promote mental health, prosocial values, and inter-group tolerance. Psychological Inquiry, 18(3), 139-156. doi:10.1080/10478400701512646

Mikulincer, M., \& Shaver, P. R. (2007b). Attachment in adulthood: Structure, dynamics, and change. New York, NY: Guilford Press.

Mikulincer, M., Shaver, P. R., \& Pereg, D. (2003). Attachment theory and affect regulation: The dynamics, development, and cognitive consequences of attachment-related strategies. Motivation and Emotion, 27, 77-102. doi:10.1023/A:1024515519160

Nolen-Hoeksema, S., \& Morrow, J. (1991). A prospective study of depression and posttraumatic stress symptoms after a natural disaster: The 1989 Loma Prieta Earthquake. Journal of Personality and Social Psychology, 61, $115-121$. doi:10.1037/0022-3514.61.1.115

Ochsner, K. N., \& Gross, J. J. (2005). The cognitive control of emotion. Trends in Cognitive Sciences, 9, $242-249$. doi:10.1016/j.tics.2005.03.010

Preacher, K. J., \& Hayes, A. F. (2004). SPSS and SAS procedures for estimating indirect effects in simple mediation models. Behavior Research Methods, Instruments, \& Computers, 36, 717-731. doi:10.3758/BF03206553 
Preacher, K. J., \& Hayes, A. F. (2008). Asymptotic and resampling strategies for assessing and comparing indirect effects in multiple mediator models. Behavior Research Methods, 40, 879-891. doi:10.3758/BRM.40.3.879

Raes, F., \& Williams, J. M. G. (2010). The relationship between mindfulness and uncontrollability of ruminative thinking. Mindfulness, 1, 199-203. doi:10.1007/s12671-010-0021-6

Schmitt, D. P., Alcalay, L., Allensworth, M., Allik, J., Ault, L., Austers, I., . . Cunen, M. A. B. (2004). Patterns and universals of adult romantic attachment across 62 cultural regions: Are models of self and of other pancultural constructs? Journal of Cross-Cultural Psychology, 35, 367-402. doi:10.1177/0022022104266105

Schmidt, R. E., Gay, P., Courvoisier, D., Jermann, F., Ceschi, G., David, M., . . Van der Linden, M. (2009). Anatomy of the White Bear Suppression Inventory (WBSI): A review of previous findings and a new approach. Journal of Personality Assessment, 91, 323-330. doi:10.1080/00223890902935738

Shaver, P. R., Lavy, S., Saron, C. D., \& Mikulincer, M. (2007). Social foundations of the capacity for mindfulness: An attachment perspective. Psychological Inquiry, 18, 264-271. doi:10.1080/10478400701598389

Shaver, P. R., \& Mikulincer, M. (2002). Attachment-related psychodynamics. Attachment \& Human Development, 4, $133-161$. doi:10.1080/14616730210154171

Shrout, P. E., \& Bolger, N. (2002). Mediation in experimental and nonexperimental studies: New procedures and recommendations. Psychological Methods, 7, 422-445. doi:10.1037/1082-989X.7.4.422

Van Dam, N. T., Earleywine, M., \& Danoff-Burg, S. (2009). Differential item function across meditators and non-meditators on the Five Facet Mindfulness Questionnaire. Personality and Individual Differences, 47, 516-521. doi:10.1016/j.paid.2009.05.005

Walsh, J. J., Balint, M. G., Smolira, D. R., SJ, Fredericksen, L. K., \& Madsen, S. (2009). Predicting individual differences in mindfulness: The role of trait anxiety, attachment anxiety and attentional control. Personality and Individual Differences, 46, 94-99. doi:10.1016/j.paid.2008.09.008

Wegner, D. M., \& Zanakos, S. (1994). Chronic thought suppression. Journal of Personality, 62, 615-640. doi:10.1111/j.1467-6494.1994.tb00311.x 